\begin{tabular}{|c|c|}
\hline \multirow{3}{*}{ 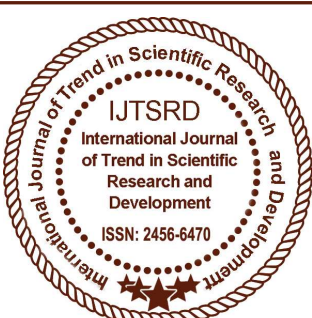 } & $\begin{array}{l}\text { International Journal of Trend in Scientific } \\
\text { Research and Development (IJTSRD) }\end{array}$ \\
\hline & International Open Access Journal \\
\hline & ISSN No: 2456 - 6470 | www.ijtsrd.com | Volume - 2 | Issue - \\
\hline
\end{tabular}

\title{
A Heart Disease Prediction Model using Logistic Regression
}

\author{
K. Sandhya Rani \\ Asst. Prof, Dhanekula Institute of \\ Engineering and Technology, \\ Ganguru, Vijayawada, Andhra \\ Pradesh, India
}

\author{
M. Sai Manoj \\ Dhanekula Institute of Engineering \\ and Technology, \\ Ganguru, Vijayawada, \\ Andhra Pradesh, India
}

\author{
G. Suguna Mani \\ Dhanekula Institute of Engineering \\ and Technology, \\ Ganguru, Vijayawada, \\ Andhra Pradesh, India
}

\section{ABSTRACT}

The early prognosis of cardiovascular diseases can aid in making decisions to lifestyle changes in high risk patients and in turn reduce their complications. Research has attempted to pinpoint the most influential factors of heart disease as well as accurately predict the overall risk using homogenous data mining techniques. Recent research has delved into amalgamating these techniques using approaches such as hybrid data mining algorithms. This paper proposes a rule based model to compare the accuracies of applying rules to the individual results of logistic regression on the Cleveland Heart Disease Database in order to present an accurate model of predicting heart disease.

KEYWORDS: heart disease prediction, logistic regression, Cleveland heart disease data base

\section{INTRODUCTION}

This paper analyzes the heart disease predictions using classification algorithms. These hidden patterns can be used for health diagnosis in medicinal data. Data mining technology afford an effective approach to latest and indefinite patterns in the data. The information which is identified can be used by the healthcare administrators to get better services. Heart disease was the most important reason of victims in the countries like India, United States. Data mining techniques like Association Rule Mining, Clustering, Classification algorithms such as Decision tree, C4.5 algorithm.
The heart disease database is pre-processed to make the mining process more efficient. The pre-processed data is classified with Regression.

\section{DATA DESCRIPTION}

The dataset consists of 15 types of attributes listed in the table 1

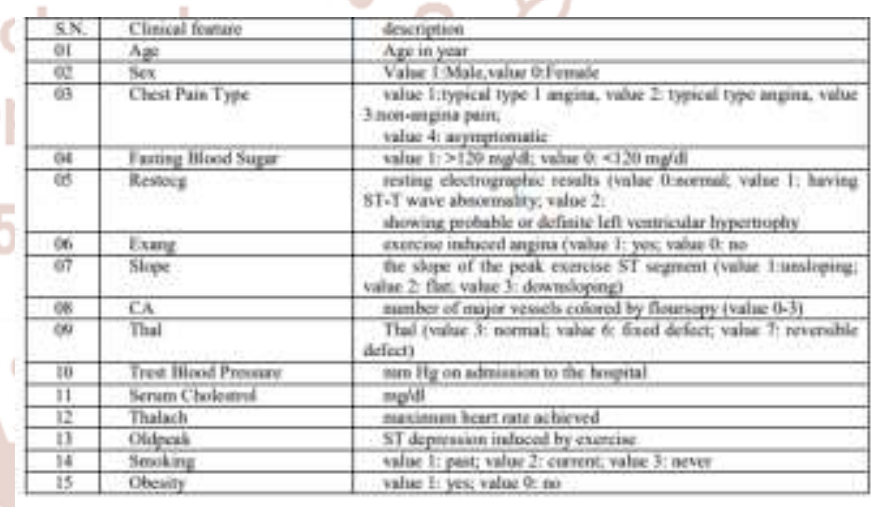

Tate 1- Clinial featien and their decriptim

All these attributes are considered to predict the heart disease, among them age and the sex are fixed attributes and all the other are modifiable attributes.

This dataset is collected from the Cleveland heart disease dataset so that we can give this dataset as the input to our study. After the dataset is given input to the study dataset undergo clustering and classification. We use logistic regression for the preprocessing of the dataset so that the outlier are detected and eliminated then it will be more efficient and accurate to predict the disease. The prediction is 
categorized into two states one is detected and the other one is not detected.

\section{PROPOSED SYSTEM}

This project analyzes the heart disease predictions using classification algorithms. These hidden patterns can be used for health diagnosis in medicinal data. Data mining technology afford an effective approach to latest and indefinite patterns in the data. The information which is identified can be used by the healthcare administrators to get better services. Heart disease was the most important reason of victims in the countries like India, United States. Data mining techniques like Association Rule Mining, Clustering, Classification algorithms such as Decision tree, C4.5 algorithm.

The heart disease database is pre-processed to make the mining process more efficient. The pre-processed data is classified with Regression

The term regression can be defined as the measuring and analyzing the relation between one or more independent variable and dependent variable. Regression can be defined by two categories; they are linear regression and logistic regression.

Logistic regression is a generalized by linear regression. It is mainly used for estimating binary or multi-class dependent variables and the response variable is discrete, it cannot be modeled directly by linear regression i.e. discrete variable changed into continuous value.

Logistic regression basically is used to classify the low dimensional data having nonlinear boundaries. It also provides the difference in the percentage of dependent variable and provides the rank of individual variable according to its importance.

So, the main motto of Logistic regression is to determine the result of each variable correctly Logistic regression is also known as logistic model/ logit model that provide categorical variable for target variable with two categories such as light or dark, slim/ healthy.

\begin{tabular}{|c|c|c|c|c|c|}
\hline \multicolumn{4}{|c|}{ 清 Logistic regression } & \multicolumn{2}{|c|}{ 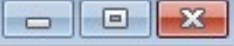 } \\
\hline A1 & & & & & \\
\hline & A & B & C & D & - \\
\hline & AGE & SMOKING & OUTCOME & & \\
\hline 1 & 28 & 0 & 1 & & \\
\hline 2 & 35 & 0 & 0 & & \\
\hline 3 & 32 & 0 & 0 & & \\
\hline 4 & 33 & 1 & 1 & & \\
\hline 5 & 41 & 0 & 1 & & \\
\hline 6 & 21 & 0 & 0 & & - \\
\hline 1 & III & $\nexists$ & & & \\
\hline
\end{tabular}

In the following example there are two predictor variables: AGE and SMOKING. The dependent variable, or response variable is OUTCOME. The dependent variable OUTCOME is coded 0 (negative) and 1 (positive).

\section{Algorithm for logistic regression}

1. Suppose we represent the hypothesis itself as a logistic function of a linear combination of inputs: $\mathrm{h}(\mathrm{x})=1 / 1+\exp (\mathrm{wTx})$ This is also known as a sigmoid neuron.

2. Suppose we interpret $\mathrm{h}(\mathrm{x})$ as $\mathrm{P}(\mathrm{y}=1 \mid \mathrm{x})$

3. Then the log-odds ratio, $\ln$ $(\mathrm{P}(\mathrm{y}=1 \mid \mathrm{x}) / \mathrm{P}(\mathrm{y}=0 \mid \mathrm{x}))=\mathrm{wT} \mathrm{x}$ which is linear

4. The optimum weights will maximize the conditional likelihood of the outputs, given the inputs.

\section{SYSTEM REQUIREMENTS}

I. HARDWARE REQUIREMENTS:-
1. System
2. Hard Disk Pentium
3. Ram
40GB

II. SOFTWARE REQUIREMENTS:-

1. Operating System : Windows

2. Coding Language : JAVA

3. Data Base : MYSQL 
International Journal of Trend in Scientific Research and Development (IJTSRD) ISSN: 2456-6470

\section{FLOW CHART}
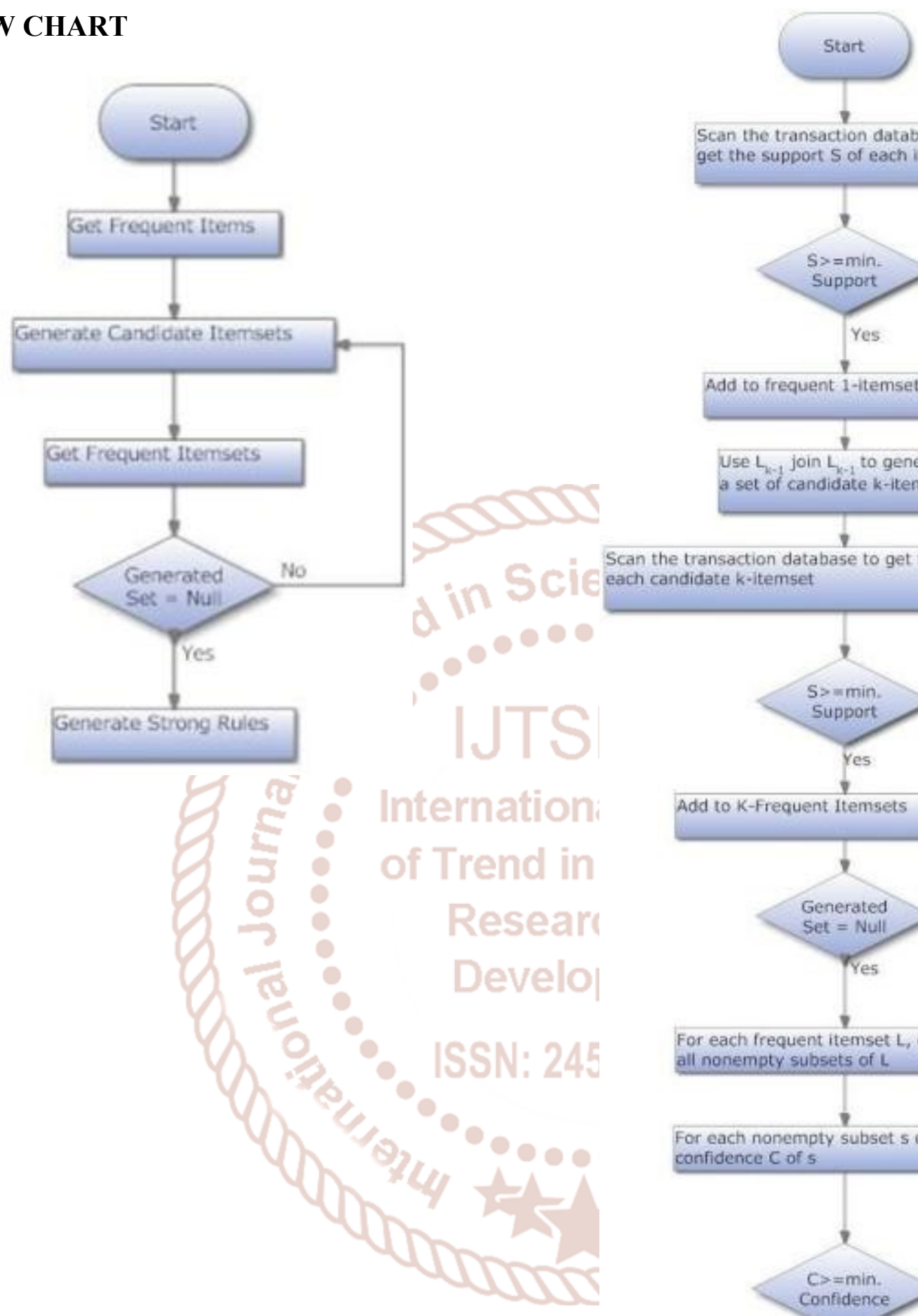

Scan the transaction database to get the support $S$ of each item each candidate $k$-itemset

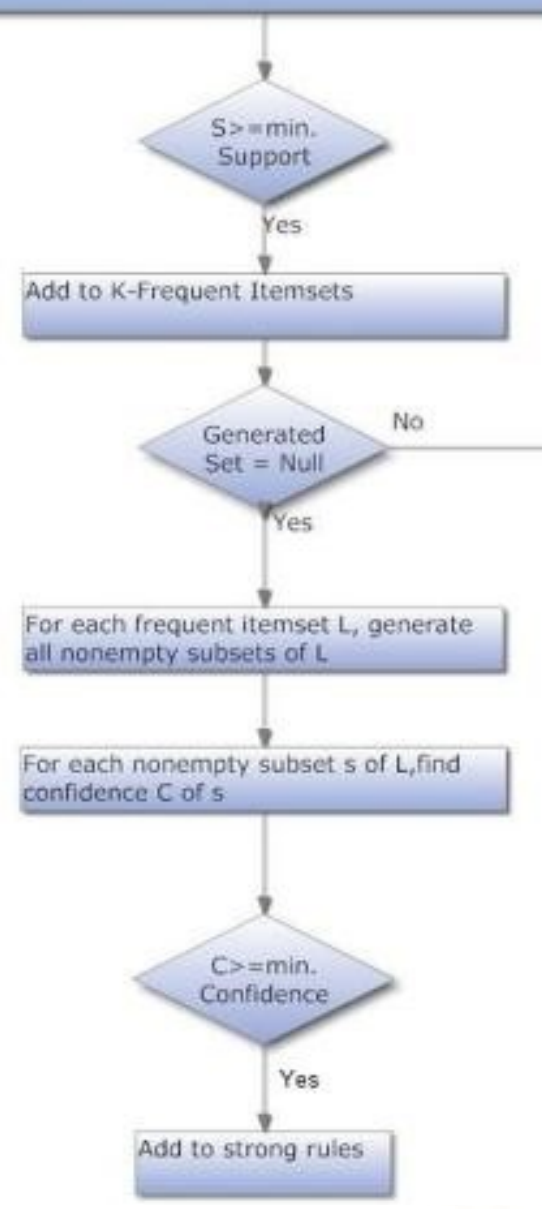

flow chart diagrams used for our study 


\section{RESULT}

\begin{tabular}{|c|c|c|c|c|}
\hline \multicolumn{2}{|c|}{ Get Data as Per Age } & Analysis Data & \multicolumn{2}{|c|}{ Predict } \\
\hline Age & Sex & Val2 & Val1 & Result \\
\hline 29 & male & 0 & 0 & Not Detected.. \\
\hline 34 & female & 0 & 0 & Not Detected. \\
\hline 34 & male & 0 & 0 & Not Detected. \\
\hline 35 & female & 0 & 0 & Not Detected. \\
\hline 35 & male & $82.666666666 \ldots$ & $2.49443825784 \ldots$ & Detected.. \\
\hline 37 & female & 0 & 0 & Not Detected. \\
\hline 37 & male & 0 & 0 & Not Detected. \\
\hline 38 & male & 92 & $8.48528137423 \ldots$ & Detected.. \\
\hline 39 & female & 69 & 22 & Detected.. \\
\hline 39 & male & 59 & 11 & Not Detected. \\
\hline 40 & male & $97.333333333 \ldots$ & $17.6635217326 \ldots$ & Detected.. \\
\hline 41 & female & 85.75 & $10.1581248269 \ldots$ & Detected.. \\
\hline 41 & male & $101.16666666 \ldots$ & $9.89528507253 \ldots$ & Detected.. \\
\hline 42 & female & 60 & 9 & Not Detected. \\
\hline 42 & male & 109 & $10.2252411001 \ldots$ & Detected.. \\
\hline 43 & female & 61 & 5 & Detected.. \\
\hline 43 & male & $101.16666666 \ldots$ & $13.1708854000 \ldots$ & Detected.. \\
\hline 44 & female & 59 & 5 & Not Detected. \\
\hline 44 & male & $109.11111111 \ldots$ & 8.88333159613... & Detected.. \\
\hline 45 & female & $83.333333333 \ldots$ & $10.8730042868 \ldots$ & Detected.. \\
\hline 45 & male & 99 & $13.6293800299 \ldots$ & Detected.. \\
\hline 46 & female & 81 & $16.5797734872 \ldots$ & Detected.. \\
\hline 46 & male & 90.25 & 18.84641875795 & Detected.. \\
\hline 47 & male & 92 & $12.0929731662 \ldots$ & Detected.. \\
\hline 48 & female & 0 & 0 & Not Detected.. \\
\hline 48 & male & 105 & $6.69991708074 \ldots$ & Detected.. \\
\hline 49 & female & 65 & 2 & Detected.. \\
\hline 49 & male & $79.333333333 \ldots$ & $5.249338858267 \ldots$ & Detected.. \\
\hline 50 & female & $76.6666666666 \ldots$ & $4.71404520791 \ldots$ & Detected.. \\
\hline 50 & male & 103.25 & $7.66077672302 \ldots$ & Detected.. \\
\hline
\end{tabular}

In this way the heart disease is predicted accurately and easily by using the logistic regression and above flowchart's. Result of the study contains 2 variables one is detected and other is not detected.

\section{CONCLUSION}

In conclusion, as identified through the logistic regression, it is a more efficient than the data mining techniques as it is combinational and more complex models to increase the accuracy of predicting the early onset of cardiovascular diseases. This paper proposes a framework using combinations of support vector machines, logistic regression, and decision trees to arrive at an accurate prediction of heart disease. Using the Cleveland Heart Disease database, this paper provides guidelines to train and test the system and thus attain the most efficient model of the multiple rule based combinations. Further, this paper proposes a comparative study of the multiple results, which include sensitivity, specificity, and accuracy. In addition, the most effective and most weighed model can be found. Further work involves development of the system using the mentioned methodologies and thus training and testing the system. Future work involves the development of a tool in such a way that the heart disease is predicted by taking as manual input (attributes) and by comparing those attributes to the database and getting the result along with the risk of disease of a prospective patient. The framework can also be extended for use on other models such as neural networks, ensemble algorithms, etc.

\section{REFERENCES}

1) Mackay,J., Mensah,G. 2004 "Atlas of Heart Disease and Stroke" Nonserial Publication, ISBN139789241562768 ISBN-10 9241562765.

2) Robert Detrano 1989 "Cleveland Heart Disease Database" V.A. Medical Center, Long Beach and Cleveland Clinic Foundation.

3) Yanwei Xing, Jie Wang and Zhihong Zhao Yonghong Gao 2007 "Combination data mining methods with new medical data to predicting outcome of Coronary Heart Disease" Convergence Information Technology, 2007. International Conference November 2007, pp 868-872.

4) Jianxin Chen, Guangcheng Xi, Yanwei Xing, Jing Chen, and Jie Wang 2007 "Predicting Syndrome by NEI Specifications: A Comparison of Five Data Mining Algorithms in Coronary Heart Disease" Life System Modeling and Simulation Lecture Notes in Computer Science, pp 129-135.

5) Jyoti Soni, Ujma Ansari, Dipesh Sharma 2011 "Predictive Data Mining for Medical Diagnosis: An Overview of Heart Disease Prediction" International Journal of Computer Applications, doi 10.5120/22372860.

6) Mai Shouman, Tim Turner, Rob Stocker 2012 "Using Data Mining Techniques In Heart Disease Diagnoses And Treatment" Electronics, Communications and Computers (JECECC), 2012 Japan-Egypt Conference March 2012, pp 173-177.

7) Robert Detrano, Andras Janosi, Walter Steinbrunn, Matthias Pfisterer, Johann-Jakob Schmid, Sarbjit Sandhu, Kern H. Guppy, Stella Lee, Victor Froelicher 1989 "International application of a new probability algorithm for the diagnosis of coronary artery disease" The American Journal of Cardiology, pp 304-310.15

8) ] Polat, K., S. Sahan, and S. Gunes 2007 "Automatic detection of heart disease using an artificial immune recognition system (AIRS) with fuzzy resource allocation mechanism and k-nn (nearest neighbour) based weighting preprocessing" Expert Systems with Applications 2007, pp 625-631.

9) Ozsen, S., Gunes, S. 2009 "Attribute weighting via genetic algorithms for attribute weighted artificial immune system (AWAIS) and its application to heart disease and liver disorders problems" Expert Systems with Applications, pp 386-392.

10) Resul Das, Ibrahim Turkoglub, and Abdulkadir Sengurb 2009 "Effective diagnosis of heart disease through neural networks ensembles" Expert Systems with Applications, pp 7675-7680. 